This is a peer-reviewed, accepted author manuscript of the following article: Pender, K., \& Yang, L. (2020). Regenerating performance of glass fibre recycled from wind turbine blade. Composites Part B: Engineering.

\title{
Regenerating performance of glass fibre recycled from wind turbine blade
}

K. Pender ${ }^{1}$, L. Yang ${ }^{2}$

University of Strathclyde, Department of Mechanical and Aerospace Engineering, 75 Montrose Street, Glasgow, G1 1XJ, United Kingdom.

${ }^{1}$ kyle.pender@strath.ac.uk

21.yang@strath.ac.uk

\begin{abstract}
The value of recycled glass fibres is reduced significantly due to loss in strength and surface functionality during recycling. This work investigates the potential of a variety of treatments to regenerate the strength and surface functionality of glass fibres recycled from retired wind turbine blades using an in-house developed fluidised bed process. It was found that soaking in hot $\mathrm{NaOH}$ solution could provide approximately a $130 \%$ increase in the tensile strength of recycled glass fibre; concluding that changes to surface morphology due to etching was the restrengthening mechanism. The interfacial adhesion between recycled glass fibre and polypropylene was also examined. A significant reduction in interfacial shear strength was observed after recycling which is attributed to the loss of original sizing after recycling. Regenerating the interfacial shear strength between recycled glass fibre and polypropylene proved challenging with the use of aminopropyltriethoxysilane coupling agent alone, however, a twofold increase in the interfacial shear strength was attained by modifying the polypropylene matrix with maleic anhydride. It was found that $\mathrm{NaOH}$ and silane treatments restored the interfacial shear strength between interfacial shear strength and epoxy to that obtained with as received glass fibres. This work shows that substantial improvements in recycled glass fibre strength and fibre-polymer adhesion can be achieved after utilising various regeneration treatments, in turn producing recycled glass fibres with significantly enhanced reinforcement potential.
\end{abstract}

Keywords: Composites, Recycling, Sustainability, wind turbine blade, Glass fibre 


\section{Introduction}

The disposal of end-of-life composite products in an environmentally friendly and economically viable manner is one of the most important challenges currently facing the composites industry. The annual global production of fibre reinforced plastics is exceeding $10 \mathrm{Mt} / \mathrm{yr}$ [1]. Thermoset based polymers account for approximately $60 \%$ of the market whereas glass fibre reinforced composites account for more than $90 \%$ of all the fibre-reinforced composites currently produced [2]. With rapid development over the past two decades, the wind energy sector has become a promising source of renewable energy. Despite this, the blades are made predominantly from glass fibre reinforced thermosets and are currently considered non-recyclable [3]. A consequence of this high demand for glass fibre reinforced plastics (GRP) is a large amount of composite production waste and end-of-life products. Annual global waste from end-of-life blades is expected to greatly increase over the coming decades, approaching $0.5 \mathrm{Mt} / \mathrm{yr}$ and $1 \mathrm{Mt} / \mathrm{yr}$ by 2030 and 2040 respectively [4]. A recycling process capable of extracting glass fibres from GRP waste, which can replace new fibres in the production of GRP, would have the benefits of reducing both the quantity of composite materials landfilled as well as saving resources required to manufacture new glass fibres.

Thermoset based composites cannot easily be reused/recycled due to their polymer crosslinking. Extensive research has been recently devoted into the development of composites recycling techniques, which have led to various recycling strategies [5-7]. Among them are thermal recycling methods, in which reinforcing fibres are liberated by incinerating polymeric matrices, followed by reuse in secondary composite components. Thermal recycling processes have the advantage of allowing for continuous and rapid waste throughput, while being tolerant to mixed and contaminated waste streams [8]. Recycled glass fibre (rGF) tend to suffer property degradation to various extents depending on the specific techniques employed. In the case of glass fibres recycled from thermal treatments, significant strength loss has been reported which renders the recycled fibres unusable in high strength components $[9,10]$. It is reported that glass fibre strength loss during thermal recycling highly dependent on recycling temperature; ranging from $50-90 \%$ of the original fibre strength [11].

It is generally recognised that damage to glass fibre surface, such as flaw generation and growth, during thermal recycling is significant in the fibre strength degradation. It has been demonstrated by Yang et al. that removing this damaged layer with hydrofluoric acid can significantly improve the tensile strength of thermally weaken glass fibres [2]. Similarly, Thomason et al. established that $75 \%$ of the strength of thermally recycled glass fibres could be recovered by treating with hot $\mathrm{NaOH}$ solution [12]. 
This paper presents results showing the ability of hot $\mathrm{NaOH}$ to significantly increase the strength of glass fibres thermally recycled from wind turbine blade scrap using an in-house developed fluidised bed recycling process. The surface morphology of glass fibres after $\mathrm{NaOH}$ treatments was observed using SEM. rGF was also treated in aminopropyltriethoxysilane (APS) to improve the interface adhesion with polymer matrices. The effect of APS treatments on rGF tensile strength and interfacial shear strength (IFSS) with polypropylene (PP) and epoxy were also investigated. These polymers were selected for investigation due to their wide spread use as matrix materials in a variety of GRP applications and industries.

\section{Experiment}

\subsection{Materials}

The influence of thermal weakening and subsequent regeneration treatments was studied on glass fibres from three sources: 1) glass fibre thermally conditioned statically within a muffle furnace, 2) glass fibres recycled from in-house prepared composites (IH-rGF) and 3) glass fibres recycled from an end-of-life wind turbine blade (WBrGF). The materials used and thermal history in each case is shown in Table 1.

In-house prepared glass fibre reinforced epoxy (GF-EP) composites were produced by infusing an E-glass fibres tri-axial $\left(0^{\circ} /-45^{\circ} / 45^{\circ}\right) 3$-ply mat supplied by Hexcel Reinforcements UK Ltd with PRIME 27 Resin and PRIME 20LV extra slow hardener supplied by Gurit. After ashing in a furnace, it was established that the resulting GFEP had a fibre weight fraction of $60 \%$. The cured GF-EP feedstock was cut to $50 \times 15 \mathrm{~mm}$ so the recycled fibres were long enough to be tested with a $20 \mathrm{~mm}$ gauge length.

A $25 \mathrm{~kg}$ section of an end-of-life offshore wind turbine blade was also sourced and used as the real-world GRP scrap for this work. The material was taken from the blade shell, approximately midway along the blade length and comprised of continuous glass fibre reinforced epoxy sandwiching a balsa wood centre. By ashing a small amount in a furnace, it was established that the fibre weight fraction of the part was $68 \%$, with the remaining mass being a combination of wood and epoxy. The blade required size reduction prior to recycling in the fluidised bed rig and was cut into regular pieces using a water jet cutter. Figure 1 shows both types of GRP used in this study after downsizing prior to recycling in the fluidised bed.

SABIC® PP 579 S PP, supplied by Saudi Basic Industries Corporation (SABIC), was used to characterise the IFSS between PP and glass fibres. A Prism TSE twin screw extruder was used to blend SABIC® PP 579 S PP 
and Polybond 3200 maleic anhydride grafted polypropylene (MAPP) at 0, 0.5, 4 and 12\% MAPP. The barrel temperatures were set to $170-230^{\circ} \mathrm{C}$ and the screw speed was set to $100 \mathrm{rpm}$. $\mathrm{NaOH}$ pellets and $37 \%$ hydrochloric acid $(\mathrm{HCl})$ were supplied by VWR and APS by Sigma-Aldrich.

\subsection{Thermal treatment}

It is well understood that glass fibres suffer mechanical and thermal weakening [13], with both imposed during recycling within the fluidised bed process. The degree to which each influences the rGF strength was investigated. A bundle of fibres extracted from the preform was thermally conditioned in a Carbolite CWF 1200 muffle furnace at $500{ }^{\circ} \mathrm{C}$ for $25 \mathrm{~min}$, which is estimated to approximate the maximum latency time of glass fibres in the fluidised bed reactor. This allowed the thermal effect alone to be isolated and the additional influence of mechanical damage on rGF strength could be inferred.

\subsection{Recycling glass fibre reinforced epoxy using fluidised bed}

Figure 2 shows a schematic of the in-house fluidised bed recycling process. The thermosetting polymer matrix is thermally decomposed within the fluidised bed reactor, which comprises silica sand fluidised with air pre-heated using an electric heater. The composite feedstock is fed into the reactor through an access pipe, located above the expanded bed. The fluidising air is supplied to the reactor via a centrifugal fan and is sufficient to entrain the liberated glass fibres from the bed and into the reactor freeboard. An induced draft fan is used to draw the glass fibres and polymer volatiles from the freeboard and to keep the reactor under a slight negative pressure. The glass fibres are recovered from the gas stream using a cyclone separator. The bed temperature, static bed height and fluidisation velocity remained constant throughout this work at $500{ }^{\circ} \mathrm{C}, 150 \mathrm{~mm}$ and $1.5 \mathrm{~m} / \mathrm{s}$ respectively. Further details on the fluidised bed system used are described by Pender and Yang [14].

\subsubsection{Alkaline treatment}

Solutions of various concentrations were prepared by dissolving $\mathrm{NaOH}$ pellets in deionised water. Throughout the investigation, $80 \mathrm{~g}$ of glass fibres were treated in $1 \mathrm{~L}$ of $\mathrm{NaOH}$ solution. The solution was pre-heated in a sealed polypropylene container in an AX60 carbolite oven. After reaching $95{ }^{\circ} \mathrm{C}$, the solution was poured over 
the glass fibres, fully immersing them. The $\mathrm{NaOH}$ solution-glass fibre mixture was then re-sealed and returned to the oven at $95{ }^{\circ} \mathrm{C}$ for various treatment times. After the desired treatment time, the fibres were drained and rinsed in $10 \mathrm{vol} \% \mathrm{HCl}$. To remove residue accumulated during the chemical treatments, the fibres were rinsed once in 1 $\mathrm{L}$ of $95^{\circ} \mathrm{C}$ water. The $\mathrm{NaOH}$ treated fibres were then dried at $110^{\circ} \mathrm{C}$ for $1 \mathrm{hr}$.

\subsubsection{Silane treatment}

In an attempt restore surface functionality after thermal recycling and/or $\mathrm{NaOH}$ treatment, the rGF were submerged in 1 vol\% APS solution for $15 \mathrm{~min}$. The APS solution was prepared with deionised water and the aqueous solution was aged for $24 \mathrm{hr}$ before use. Glass fibres were drained from the APS solution then dried at $110^{\circ} \mathrm{C}$ for $15 \mathrm{~min}$

\subsection{Single fibre tensile test}

All single fibre tensile testing was performed following ASTM C1557-03 and practice developed in [15]. Tensile strength of at least 30 single glass fibres for each sample type were characterised at $20 \mathrm{~mm}$ gauge length. The cross sectional area of each glass fibre was assumed circular and found by capturing an image of the fibre using an Olympus GX51 optical microscope. The diameter was then measured using ImageJ software. Tensile testing of the glass fibres was performed using a Testometric M250-2.5CT with a $5 \mathrm{~N}$ load cell at a strain rate of 1.5 $\% /$ min at ambient conditions.

\subsection{Microbond test}

In order to assess the interfacial adhesion between glass fibre and polymer materials, the apparent IFSS was measured using a laboratory-developed microbond test technique. The IFSS was measured with both PP and epoxy matrices. The procedure of forming a PP droplet on a glass fibre and the development of the microbond test have been previously reported $[13,16]$. The procedure for preparing epoxy microbond specimens is outlined in [17]. The apparent IFSS was determined using the maximum forced recorded along with the corresponding fibre diameter and embedded length for each sample. Approximately 30 tests were carried out to obtain the average IFSS for each sample. 


\subsection{Scanning electron microscopy}

A Hitachi SU6600 SEM was used to analyse the surface morphology of glass fibres. Carbon adhesive tape was used to glue the specimens on aluminium stubs. The samples were gold coated to prevent charging when they were analysed under SEM.

\section{Results and discussion}

\subsection{Glass fibre strength regeneration}

\subsubsection{Tensile strength of rGF from in-house prepared composites}

Initially $\mathrm{NaOH}$ treatments were performed on both 1) glass fibre after thermal conditioning and 2) rGF from inhouse prepared composites (IH-rGF). The $\mathrm{NaOH}$ treatment time was kept constant at 10 min and solution concentrations of $1.5,3$ and $5 \mathrm{~mol} / \mathrm{L}$ were used. The treatment time was initially selected as Thomason et al. observed a $130 \%$ increase in tensile strength of glass fibres thermally conditioned at $500{ }^{\circ} \mathrm{C}$ when treated with 3 $\mathrm{mol} / \mathrm{L} \mathrm{NaOH}$ solution for $10 \min [12]$.

Figure 3 gives the single fibre tensile strength following treatment in the $\mathrm{NaOH}$ solutions. The strength of glass fibre after thermal conditioning increases with $\mathrm{NaOH}$ concentration, similar to that observed in [18]. Treating with $1.5,3$ and $5 \mathrm{~mol} / \mathrm{L}$ solution yields a 14,33 and $48 \%$ increase in tensile strength respectively, relative to fibres not treated with $\mathrm{NaOH}$. Higher concentrations may continue to improve the strength of these fibres since a plateau does not appear to have been reached in the range of concentrations studied. Nagel also performed $\mathrm{NaOH}$ treatments on glass fibres thermally conditioned at $500{ }^{\circ} \mathrm{C}$ for $25 \mathrm{~min}$ and reported a strength of around $1.2 \mathrm{GPa}$ after thermal conditioning alone [19]. Similar to this work, Nagel observed around a 33\% increase in fibre strength after treating with $3 \mathrm{~mol} / \mathrm{L} \mathrm{NaOH}$ solution for $10 \mathrm{~min}$ [19].

The $\mathrm{NaOH}$ treatments used in Figure 3 show little effect on the strength of IH-rGF, with a relatively consistent single fibre strength of $0.5-0.6 \mathrm{GPa}$. It has been hypothesised that the reaction of silica in the glass fibre with hydroxide ions from the $\mathrm{NaOH}$ solution smooths and/or removes the severe surface flaws that manifest during exposure to elevated temperatures, and thus increases the tensile strength of the fibre [12,18]. It is likely that there 
are more severe flaws present on the surface of the recycled fibres compared to the thermally conditioned, given their significantly lower strength.

The surface of fibres recycled in the fluidised bed was further studied under SEM, as seen in Figure 4. The presence of apparent damage was found on the surface of IH-rGF in the form of scratches and depressions. No such features were observed on the surface of glass fibres simply thermally conditioned within a furnace at the same temperature, suggesting the damage is a result of mechanical attrition during recycling. Given the high hardness of silica sand, abrasion from this sand in the fluidised bed may be a likely cause. Pickering et al. [11], Fenwick [20] and Kennerley [21, 22] reported the properties of glass fibres recycled using a fluidised bed, however, no such features were discussed. The depth of the damage cannot be determined using SEM, however the topography of the fibre surface could be further explored using atomic force microscopy.

Although it is well understood that the measured strength of glass fibres is controlled by surface flaws (extrinsic strength) [23], to the best of the authors knowledge, direct observation of such features on glass fibres have not been reported. It is unclear whether the detectable damage is strength limiting or to what extent (if any) it contributes to the weakening of the recycled fibres. Since the IH-rGF are considerably weaker than glass fibre after thermal conditioning at the same temperature, the additional damage observed in Figure 4 may indeed influence the fibre strength. In light of this, the efficacy of $\mathrm{NaOH}$ at increasing recycled fibre strength could be reduced due to the presence of more severe flaws on the surface of these fibres.

Linear-elastic fracture mechanics can be used to estimate the flaw length in the glass fibres. The flaw length $(c)$ is proportional to the measured fibre tensile strength $\left(\sigma_{f, a v}\right)$ via Eqn. (1), where $K_{I C}$ is the mode I fracture toughness and $Y$ is a geometric stress concentration factor [24].

$$
c=\frac{1}{\pi}\left(\frac{K_{I C}}{\sigma_{f, a v} Y}\right)^{2}
$$

$K_{I C}$ of E-glass fibre was found by Feih et al. to be approximately $0.91 \mathrm{MPam}^{1 / 2}$ [24]. $Y$ is dependent on the shape of the flaws on the glass surface, which is unknown with and without thermal/mechanical weakening. Halfpenny $(Y=0.73)$ and straight $(Y=1.12)$ flaw geometries represent the minimum and maximum values of $Y$, where any intermediate flaw shape will be $0.73<\mathrm{Y}<1.12$ [24]. In this study, both $Y$ values were used and a range of flaw lengths for each sample based on the average tensile strength was estimated. Assuming the fibre is uniformly etched radially, the reduction in diameter required to remove a flaw of length, $c$ is given in Eqn. (2), where $D_{o}$ is the initial fibre diameter. 


$$
\text { Diameter reduction }(\%)=\frac{2 c}{D_{o}} \times 100
$$

Table 2 gives the range of estimated flaw lengths on the surface of the various glass fibre samples as well as the relative reduction in diameter required to remove them. As expected from Eqn. (1), flaw length and required diameter reduction increase significantly with a drop in fibre strength.

Given the lack in strength increase under the conditions used in Figure 3, IH-rGF were treated with $\mathrm{NaOH}$ for extended times. Figure 5 gives the strength and relative diameter of IH-rGF after treatment with a 5 mol/L solution of $\mathrm{NaOH}$ for 5, 10, 20, 60, 120 and $180 \mathrm{~min}$. There is a clear increase in tensile strength with treatment time when treating for longer than $20 \mathrm{~min}$. The fibre strength appears to begin to plateau at $1.25 \mathrm{GPa}$ after treating for 180 min, suggesting only minimal, if any, additional strength gain can be achieved by extending treatment duration. Figure 5 also shows the change in IH-rGF diameter after the $\mathrm{NaOH}$ treatment. The reduction in IH-rGF diameter with treatment time is more pronounced when extending the range of $\mathrm{NaOH}$ treatment times. Similar to the tensile strength data, significant effect of the $\mathrm{NaOH}$ on IH-rGF diameter is not observed for treatments shorter than 60 $\min$.

It was anticipated that removing additional surface material could lead to re-strengthening of recycled fibres; therefore, additional concentrations of $\mathrm{NaOH}$ solutions were applied to IH-rGF at extended treatment times. $\mathrm{NaOH}$ concentrations of 1.5, 3, 7 and $10 \mathrm{~mol} / \mathrm{L}$ were used for 60,120 and $180 \mathrm{~min}$. Figure 6 gives the tensile strength of IH-rGF then treated with $\mathrm{NaOH}$ at the various concentrations and times. All concentrations investigated, except $1.5 \mathrm{~mol} / \mathrm{L} \mathrm{NaOH}$ solution, increased the strength of IH-rGF. In agreement with Figure 3, the effectiveness of $\mathrm{NaOH}$ tends to increases with $\mathrm{NaOH}$ concentration. IH-rGF treated with $1.5 \mathrm{~mol} / \mathrm{L} \mathrm{NaOH}$ solution may exhibit an increase in strength if the treatment times were extended further; given the dependence of rate of strength increase on $\mathrm{NaOH}$ concentration.

It appears there is a maximum strength increase for 7 and $10 \mathrm{~mol} / \mathrm{L}$ treatments, where extending the treatment time does not improve the fibre strength. This plateau occurs more rapidly when higher concentrations are used. Figure 6 shows the strength of fibres treated at 7 and $10 \mathrm{~mol} / \mathrm{L}$ appear to plateau after treatments lasting 120 and $60 \mathrm{~min}$ respectively. No plateau is observed for $5 \mathrm{~mol} / \mathrm{L}$ treatments, however, the rate of strength increase appears to reduce after treatment of $120 \mathrm{~min}$. Furthermore, no plateau is observed for $3 \mathrm{~mol} / \mathrm{L}$ treatments which approximate a linear increase in strength within the treatment times studied. Extended treatments at 3 and $5 \mathrm{~mol} / \mathrm{L}$ are required to determine if/when the fibre strength plateaus when using these concentrations. 
The maximum possible strength increase may in fact be the same for all concentrations, with lower concentrations requiring longer treatments to converge. This is better seen in Figure 7, which plots tensile strength of IH-rGF against $\mathrm{NaOH}$ concentration. Although Figure 6 shows that the rate of strength regeneration increases with concentration, there does seem to be an asymptotic strength value in Figure 7 as time elapses. IH-rGF treated for 120 and $180 \mathrm{~min}$ plateau in strength when 7 and $5 \mathrm{~mol} / \mathrm{L}$ solution is used respectively. This is in contrast with 60 min treatments where no plateau is observed within the range of $\mathrm{NaOH}$ solution concentration studied. Such a plateau in strength may also be observed for 60 min treatments at higher $\mathrm{NaOH}$ concentrations, allowing for a more rapid treatment.

Under the conditions investigated, the maximum IH-rGF tensile strength attained was approximately $1.4 \mathrm{GPa}$ after treating for $120 \mathrm{~min}$ at $7 \mathrm{~mol} / \mathrm{L}$. While this is a significant increase in the fibre strength, it is still considerably lower than the original strength of $2.55 \mathrm{GPa}$. It was previously demonstrated by Thomason and Kalinka that the actual average strength of fibres in a commercial $4 \mathrm{~mm}$ chopped glass product was as low as $1.5 \mathrm{GPa}$ at a gauge length of $2 \mathrm{~mm}$ [25]. It is well established that there is an inverse relation between fibre tensile strength and gauge length, therefore, the regenerated strength of $1.4 \mathrm{GPa}$ at $20 \mathrm{~mm}$ gauge length found in this work may provide a fibre strength distribution that is higher than that obtained in typical commercial discontinuous glass fibre products.

Figure 8 shows the IH-rGF diameter after $\mathrm{NaOH}$ treatment at the various times and concentrations used in Figure 6. The trend lines represent second order polynomials with a minimum $\mathrm{R}^{2}$ value of 0.91 . IH-rGF treated with 1.5 mol/L solution exhibit no significant change in diameter until treated for $180 \mathrm{~min}$. All treatments which exhibit an increase in fibre strength in Figure 6, also show a significant reduction in fibre diameter. Both fibre diameter reduction and rate of reduction tend to increase with treatment time as shown in Figure 8. Yang et al. observed an inverse relation between rate of fibre reduction and treatment time when etching glass fibre with HF [2]. This was attributed to the build-up of insoluble residue particles on the fibre surface masking the fibre surface and impeded the etching process over time. However, this does not seem to occur when using $\mathrm{NaOH}$ within the treatment times studied.

The observations made in Figure 8 are in line with Bashir et al. who examined the kinetics of dissolution of glass fibres in $\mathrm{NaOH}$ solution, finding that a radial diffusion model does not describe the reaction well [26]. It was concluded that during the reaction, a product layer was formed on the surface, likely to have been comprised of sodium silicates. Due to the corrosive $\mathrm{NaOH}$ solution it is likely that the diffusion of hydroxide ions through this 
layer occurred rapidly (i.e. not a rate-determining step). Furthermore, the product silicates are highly soluble and are unlikely to sufficiently increase in thickness to impede the glass dissolution reaction [26]. Figure 8 shows that, in general, higher concentration treatments more rapidly remove the glass fibre surface. This can be attributed to an increase in hydroxide density with $\mathrm{NaOH}$ concentration. Higher hydroxide density increases the probability that more collisions with silica (of the glass surface) will be sufficiently energetic to cause a reaction and cleave the silica network. The mechanism of hydroxide ion attack on silica network is presented in Eqn. (3) [26].

$$
[-\mathrm{Si}-\mathrm{O}-\mathrm{Si}-]+\mathrm{OH}^{-} \stackrel{\Delta}{\rightarrow}[-\mathrm{SiO}]^{-}+[-\mathrm{Si}-\mathrm{OH}]
$$

Figure 9 shows SEM images of IH-rGF with and without $\mathrm{NaOH}$ treatment at $7 \mathrm{~mol} / \mathrm{L}$ for $2 \mathrm{hr}$. The $\mathrm{NaOH}$ appears to substantially modify the glass fibre surface, which was observed to be more prominent on fibres treated with higher concentrated solutions. This can be attributed to hydroxide ions corroding the silica network as outline in [27-29]. The corrosion appears to be irregular on the fibre surface, creating the pits clearly seen in Figure 9. No reference to pitting on the surface of alkali treated glass fibre could be found in the literature. The development of such features through non-uniform surface etching may be responsible for the apparent limit on strength regeneration and is discussed in more detail below.

Figure 10 shows the surface of the $\mathrm{NaOH}$ treated fibre in Figure 9 under higher magnification. Unlike recycled only fibres, the surface of fibres treated with $\mathrm{NaOH}$ appear uneven and could be due to the glass surface itself becoming rough after being etched by $\mathrm{NaOH}$. This observation is in agreement with Bashir et al. who, using atomic force microscopy, measured surface roughness of thermally conditioned glass fibres rise from around 2 to $23 \mathrm{~nm}$ after treating in a $3 \mathrm{~mol} / \mathrm{L} \mathrm{NaOH}$ solution for just $30 \mathrm{~min}$ [18]. As with the pitting seen in Figure 9, these features are not fully understood and additional studies are required to determine the cause of these phenomena and predict their influence on the mechanical properties of glass fibres.

Figure 11 gives a plot of the regenerated strength of IH-rGF as a function of fibre diameter reduction by $\mathrm{NaOH}$ treatments. IH-rGF treated with $1.5 \mathrm{~mol} / \mathrm{L}$ solution have been omitted, as they do not show any improvement in strength. In agreement with [2], this work demonstrates that removal of the surface layer of thermally recycled glass fibre can significantly improve its tensile strength. Higher concentrated treatments reach a maximum regenerated strength, after which additional removal of the glass surface is no longer beneficial. This may also be the case for 3 and $5 \mathrm{~mol} / \mathrm{L}$ treatments however the rate of diameter reduction at these concentrations is lower and was not observed within 180 min. 
Although there appears to be a trend between tensile strength and diameter reduction, this is only distinct within a given concentration of $\mathrm{NaOH}$. The inconsistency in strength increase and diameter reduction between concentrations can be observed in Figure 11. If the strength increase mechanism solely involved removal of the surface flaws, it would be expected that the strength of fibres treated at various concentration would be similar, when approximately the same volume of material has been removed. This is not the case as revealed by the results in Figure 11 and made particularly clear for $\mathrm{NaOH}$ treatments of $60 \mathrm{~min}$. According to fracture mechanics given in Table 2, these data points are in the range where flaws on the rGF surface are still likely to be present. The disparity in tensile strength may therefore be due to flaw modification rather than complete removal. Higher concentrated $\mathrm{NaOH}$ solutions may smooth the severe flaws on the surface more rapidly, reducing stress concentrations during testing [30]. This is in agreement with Bashir et al. and Nagel who observed no detectable reduction in diameter when regenerating the strength of thermally conditioned glass fibres with $\mathrm{NaOH}[18,19]$.

In Figure 11, the strength of IH-rGF treated in 7 and $10 \mathrm{~mol} / \mathrm{L} \mathrm{NaOH}$ do plateau at approximately the diameter reduction range given in Table 2. Enough of the surface has been removed to eliminate all surface flaws caused during thermal recycling. The reason for the apparent upper limit on strength regeneration is still unclear. One may expect the resulting glass fibre surface to be absent of flaws and the strength approach that of pristine fibres [23]. It is well established in the literature however that $\mathrm{NaOH}$ solution is a corrosive environment for glass fibre, which can substantially weaken the fibre [27-29, 31]. Jianxun Liu et al. propose hydroxide ions can disrupt the continuity of the glass network therefore reducing the fibre strength [27]. Treating with $\mathrm{NaOH}$ may therefore improve the strength of recycled fibres by removing the highly damaged outer surface while creating features on the new exposed outer surface (as seen in Figure 9 and Figure 10), which limits the ultimate potential for strength regeneration using this particular treatment. Figure 11 shows that IH-rGF treated with 3 and $5 \mathrm{~mol} / \mathrm{L}$ continue to increase in strength beyond the estimated diameter reduction required to remove all flaws induced during recycling. With the severe flaws removed, it is unclear why the strength of fibres treated with the lower concentrated $\mathrm{NaOH}$ do not converge with those treated in 7 and $10 \mathrm{~mol} / \mathrm{L}$ solution. It would appear that IH-rGF treated with lower concentrated solutions require additional removal of surface material to replicate the strength increase provided by higher concentrated treatments. 


\subsubsection{Tensile strength of rGF from wind turbine blade}

Figure 12 gives the tensile strength of glass fibres recycled from the wind turbine blade (WB-rGF) before and after treatment in $7 \mathrm{~mol} / \mathrm{L} \mathrm{NaOH}$ solution for $2 \mathrm{hr}$. Given the size of the wind turbine blade recyclate, single fibre tensile testing was carried out at a gauge length of $5 \mathrm{~mm}$. The strength of IH-rGF was also tested at $5 \mathrm{~mm}$ for a comparison and the data is included in Figure 12. The tensile strength of WB-rGF approximates those of the IH-rGF, with treatment in $\mathrm{NaOH}$ solution significantly increases the strength of WB-rGF. With an average tensile strength of $1.7 \mathrm{GPa}$, the WB-rGF respond even more favourably to the $\mathrm{NaOH}$ strength regeneration treatment than the IH-rGF. Figure 12 validates the effectiveness, and potential for, $\mathrm{NaOH}$ solution to be used as a strength regeneration treatment on glass fibres recycled from commercial GRP scrap.

\subsection{Interface regeneration}

\subsubsection{IFSS with polypropylene}

Figure 13 shows the IFSS between PP and glass fibre recycled from in-house prepared composites after $\mathrm{NaOH}$ and APS treatments. The $\mathrm{NaOH}$ treatment used throughout Figure 13 is $7 \mathrm{~mol} / \mathrm{L}$ for $2 \mathrm{hr}$. As a control, Figure 13 gives the IFSS when using new glass fibres, denoted "New". New glass fibres were supplied by Owens Corning in a roving. These were selected as a control in this work as they were supplied either water only sized or coated with APS alone, opposed to a commercial sizing blend.

The IFSS with the IH-rGF prior to any treatment approximates that reported by Nagel after thermal conditioning [19]. The new, unsized glass fibres, exhibit significantly weaker interfacial adhesion than the IH-rGF and closely matches that reported by Thomason [32] and Min et al. [33]. With a fluidised bed temperature of $500{ }^{\circ} \mathrm{C}$, the organic portion of the silane coupling agent present on the fibres in the recyclate will decompose during recycling [13]; however, the siloxane network which is deposited on the fibre surface will remain. Although there no longer remains amino functional groups for the polymer to interact with chemically, it is yet unclear how this deposited siloxane layer (after thermal conditioning/recycling) influences the IFSS with PP.

APS treatment alone slightly increases the IFSS with IH-rGF, however, considering the measured error; it is not clear how significant the apparent rise in IFSS is after coating in APS. This is in contrast with new glass fibres, which, when treated with APS, exhibit a near threefold increase in IFSS. Exposing glass fibres to elevated 
temperatures has been demonstrated to remove surface hydroxyl groups through condensation [34, 35]. Given that APS is believed to bond with the glass fibre through condensation with these surface hydroxyl groups, the effectiveness of APS as a coupling agent may be compromised when used with thermally recycled glass fibres.

Thomason et al. [12] and Nagel [19] observed a significant increase in IFSS between thermally conditioned glass fibres and unmodified PP when APS was used. This is contradicted by other studies [36-39], which found that amino-silane coupling agents alone do not improve the adhesion with unmodified PP; concluding that PP has to be modified with an acidic group to interact with APS. Although PP may not chemically bond with APS, weaker intermolecular forces (such as Van der Waals forces) may increase adhesion, specifically via the electronegative amino functional group.

No increase in IFSS for $\mathrm{NaOH}$ treated IH-rGF was observed when using APS. According to the literature, a product of etching with $\mathrm{NaOH}$ is silanol on the glass surface, caused by the cleaving of siloxane (see Eqn. (3)) [26]. It may therefore be expected that the IFSS with IH-rGF would improve as result of $\mathrm{NaOH}$ treatment when coated in APS, due to higher hydroxyl group concentration and better APS bonding. This was not observed; moreover, the IFSS with rGF is significantly higher than with $\mathrm{NaOH}$ treated IH-rGF when APS is used.

When comparing the effect of APS on IFSS with PP in Figure 13, it is worth reiterating that fibres used for the new and IH-rGF data points are from different sources/suppliers. As such, comparing the exact values for IFSS may be less valuable than observing the trends themselves. It is clear from in Figure 13 that using APS significantly improves the IFSS when used with new fibres, whereas IH-rGF do not respond so favourably.

The effect of modifying the PP matrix with MAPP on the IFSS with IH-rGF treated in NaOH (7 mol/L for $2 \mathrm{hr})$ and APS was investigated. Figure 14 shows that the IFSS is improved through the modification with MAPP, with a maximum value of approximately $15 \mathrm{MPa}$ was observed at loadings of $4 \mathrm{wt} \%$ or greater. It is reported in other studies $[36-38,40]$ that using MAPP modified PP with un-silanised glass fibres can still increase adhesion when compared to unmodified PP alone. It is therefore unclear whether the rise in IFSS observed in Figure 14 is due to acid-basic interaction with maleic anhydride and amino function group of APS or the glass surface itself. Despite the uncertainty in the underlying mechanism, Figure14 suggests that modifying PP matrix with MAPP could improve the strength of rGF-PP through increased interfacial adhesion. 


\subsubsection{IFSS with epoxy}

The IFSS between rGF from wind turbine blade and epoxy were measured using the microbond technique. WBrGF treated with and without $\mathrm{NaOH}$ were tested, where the $\mathrm{NaOH}$ treatment used was $7 \mathrm{~mol} / \mathrm{L}$ solution for $2 \mathrm{hr}$. Figure 15 gives the IFSS of WB-rGF with epoxy, before and after $\mathrm{NaOH}$ and APS treatments. Again, Owens Corning water and APS sized fibres were used as the "New" control.

Although a different epoxy system was used in [41], the IFSS with APS coated new glass fibres given in Figure 15 approximates that reported by Minty et al. [41]. WB-rGF without any post-treatments exhibit a significant reduction in IFSS with epoxy; approximately $60 \%$ of new glass fibres sized with APS. It is shown in the literature that exposure to typical thermal recycling temperatures degrades silanes present on glass fibres [13, 40, 42-44]. The sizing present on fibres in the recyclate has been rendered ineffective as a coupling agent after recycling, given that the IFSS with these fibres approximates that of unsized new fibres. In agreement with the literature, it appears that the silane present in the recyclate has, to some degree, thermally degraded during recycling. The IFSS measured with the untreated WB-rGF is in fact slightly lower than that found with unsized new fibres. Undecomposed epoxy residue (likely char) on the surface of the recycled fibres may be the cause for this disparity. This surface residue can be seen under SEM in Figure 9. Although chemical bonding at the interface is not expected without a coupling agent, the epoxy and surface silanol groups can still experience polar interaction, via hydrogen bonding [45]. Residue on the fibre surface may inhibit such interactions and in turn reduce the measured IFSS. Factors such as wetting, adsorption and diffusion may also be affected by the presence of surface residue contamination. It should be noted that the fibres under comparison are not of the same origin and as such may have difference in composition and production history. It is feasible that such inconsistencies alone could also account for the discrepancy in IFSS.

Figure 15 would initially suggest that applying APS to WB-rGF does not lead to a significant increase in adhesion with epoxy, however, this reported IFSS value should be taken as a "minimum" IFSS and does not represent the true value. For all specimens, the WB-rGF itself failed during testing prior to the epoxy microdroplet debonding as a result of the low fibre strength, reported in Figure 12. Efforts were made to reduce the debond force by minimising the fibre-epoxy interface area, however, this produced non-spherical microdroplets with inconsistent geometry which were unsuitable for analysis. From Figure 15 it can be concluded that applying APS to the surface of WB-rGF indeed increases IFSS with epoxy, but to what extent cannot be established without utilising an alternative testing method. 
Figure 15 shows that WB-rGF treated in $\mathrm{NaOH}$ solution yields an IFSS comparable to that of APS coated new glass fibres. The increase in IFSS must be induced by treating the WB-rGF in NaOH solution; however, it is unclear if the improvement in IFSS is due to chemical or physical interaction (or both). It was observed under SEM in Figure 9 and Figure 10 that etching in concentrated $\mathrm{NaOH}$ solution resulted in significant roughening of the fibre surface. Moreover, Bashir et al. observed an increase in the roughness of glass fibre surfaces after soaking in $\mathrm{NaOH}$ solution [18]. As shown in Figure 9, these features were not found on the surface of untreated IH-rGF. The observed increase in fibre surface roughness after $\mathrm{NaOH}$ may increase the IFSS given in Figure 15 by 1 ) providing a higher actual fibre-polymer interfacial area than the measured apparent interfacial area and/or 2) increasing fibre polymer mechanical interaction. An increase in friction would produce a higher IFSS and provide one possible explanation for the observations in Figure 15. Similarly, oxidation of carbon fibre can produce pits and corrugations on the fibre surface, which can be used to mechanically anchor polymer matrices and improve stress transfer to the fibre [46].

Figure 13 shows that, unlike epoxy, the IFSS is not increased with PP as a result of $\mathrm{NaOH}$ treatment alone. If mechanical anchoring due to surface roughness causes improved adhesion with epoxy, one could deduce the same phenomenon would be observed with PP matrices. As discussed above, the level of adhesion is controlled by a combination of complex mechanisms acting collectively at the polymer/fibre interface. Factors such as increased wettability and/or chemical interactions with epoxy may work in parallel with mechanical anchoring to produce the increase in IFSS observed in Figure 15. Epoxy would be expected to wet out the small surface pits better than the comparatively viscous PP melt which would enhance any mechanical interaction occurring at the fibre surface. It is also understood that epoxy undergoes shrinkage during curing [47]; when used as a matrix medium this cure shrinkage can produce residual radial compressive stresses on the reinforcement fibre. It has been proposed that this can increase stress transfer to the fibre in turn increasing the IFSS between fibre and matrix [48]. With the introduction of surface pitting, the contribution of such forces may be enhanced, further increasing the measured IFSS.

The tensile strength of WB-rGF treated with APS is shown in Figure 16. WB-rGF with and without strength regeneration were treated within APS, where $\mathrm{NaOH}$ treatment was $7 \mathrm{~mol} / \mathrm{L}$ for $2 \mathrm{hr}$. The data in Figure 16 shows that resizing with APS does not influence tensile strength of WB-rGF. This is in agreement with Nagel who also observed no significant change in the strength of thermally conditioned glass fibres treated with APS [19]. Figure 
16 establishes that any change in GRP properties when using APS should be attributed to glass fibre-polymer adhesion rather than the strength of the recycled glass fibres.

Further work into developing this technology will involve 1) characterising the mechanical properties of GRP prepared with recycled and regenerated glass fibres to further access the efficacy of the regeneration treatments and 2) perform a techno-economic assessment of the thermal recycling and regeneration processes as a whole. Pickering et al. have analysed the profitability of the fluidised bed process for GRP recycling and concluded that such a process is indeed economically feasible at scale [11]. More recently, Meng et al. analysed the energy and environmental impacts of the fluidised bed recycling process [49], reporting significantly reduced energy demand required for fibre recycling compared to producing virgin glass fibre [50]. The lack of cost competitiveness of rGF with pristine first-pass materials is a key obstacle in the commercialisation of GRP thermal recycling technologies. For industry to adopt this technology it is therefore key that a balance must be found between the value added through regeneration treatments and the additional processing cost entailed.

\section{Conclusions}

This study investigated the use of various treatments to enhance the reinforcement potential of glass fibres recycled from in-house prepared composite and real-world wind turbine blade scrap using a fluidised bed process. It was found that soaking in hot $\mathrm{NaOH}$ solutions could significantly increase the tensile strength of recycled glass fibres. The treatment time required for strength regeneration was significantly higher for fibres recycled in the fluidised bed, compared to fibres thermally conditioned in a furnace at the same temperature. This was attributed to fibres sustaining a greater degree of damage during the recycling processes, therefore, requiring more etching to remove/sufficiently modify the surface flaws. It was found that treating $\mathrm{IH}-\mathrm{rGF}$ in $7 \mathrm{~mol} / \mathrm{L} \mathrm{NaOH}$ solution for $2 \mathrm{hr}$ yielded approximately a $130 \%$ increase in fibre tensile strength.

The use of APS as a coupling agent and PP modification with maleic anhydride were investigated as a means of promoting recycled glass fibre and PP interfacial adhesion. Using the microbond test it was observed that sizing IH-rGF with APS provided no significant increase in IFSS with unmodified PP. This suggests the APS may not be bonded to the glass surface or that the amine functional group of bonded APS has only weak interaction with the PP. Prior to proclaiming any firm conclusions, further work is required to better understand the influence of APS as a coupling agent between glass fibre and unmodified PP, especially given the disparate observation in the 
literature. The interfacial adhesion was significantly improved however with the use of maleic anhydride. A twofold increase in IFSS with IH-rFG sized with APS was observed after modifying the PP with MAPP loading of $4 \mathrm{wt} \%$.

Glass fibre-epoxy IFSS was reduced by approximately $40 \%$ after fibres were recycled from the wind turbine blade in the fluidised bed. Applying APS increased the adhesion, however, the actual IFSS could not be measured due to the weak WB-rGF breaking during microbond testing. An alternative test methodology may be required to attain an accurate IFSS measurement. It was found that $\mathrm{NaOH}$ treatment alone, originally intended to increase fibre strength, could regenerate the IFSS with epoxy to that observed with new, APS coated glass fibres. It is proposed that increased interfacial area and mechanical anchoring, facilitated by surface pitting induced by $\mathrm{NaOH}$ modification, may contribute to this rise in IFSS.

\section{Acknowledgement}

The authors gratefully acknowledge the financial support from Supergen ORE Hub (EP/S000747/1). The authors would also like to thank the reviewers for their valuable comments.

\section{References}

[1] E W, T K, M K. Composites Market Report 2015. German Federation of Reinforced Plastics; 2015. [2] Yang L, Sáez ER, Nagel U, Thomason JL. Can thermally degraded glass fibre be regenerated for closed-loop recycling of thermosetting composites? Composites Part A: Applied Science and Manufacturing. 2015;72:167-74.

[3] Jr. LM, Branner K, Petersen HN, Beauso J, McGugan M, Sørensen BF. Materials for Wind Turbine Blades: An Overview. Materials. 2017;10:1285.

[4] Liu P, Barlow C. Wind turbine blade waste in 2050. 2017.

[5] Yang Y, Boom R, Irion B, van Heerden D-J, Kuiper P, de Wit H. Recycling of composite materials. Chemical Engineering and Processing: Process Intensification. 2012;51:53-68.

[6] Job S. Recycling glass fibre reinforced composites - history and progress. Reinforced Plastics. 2013;57(5):19-23.

[7] Halliwell S. Best practice guide: End of life options for composite waste. National Composites Network; 2006.

[8] Pickering SJ. Recycling technologies for thermoset composite materials-current status. Composites Part A: Applied Science and Manufacturing. 2006;37(8):1206-15.

[9] Feih S, Boiocchi E, Mathys G, Mathys Z, Gibson AG, Mouritz AP. Mechanical properties of thermally-treated and recycled glass fibres. Composites Part B: Engineering. 2011;42(3):350-8.

[10] Thomason JL, Yang L, Meier R. The properties of glass fibres after conditioning at composite recycling temperatures. Composites Part A: Applied Science and Manufacturing. 2014;61:201-8.

[11] Pickering SJ, Kelly RM, Kennerley JR, Rudd CD, Fenwick NJ. A fluidised-bed process for the recovery of glass fibres from scrap thermoset composites. Composites Science and Technology. 2000;60(4):509-23.

[12] Thomason JL, Nagel U, Yang L, Sáez E. Regenerating the strength of thermally recycled glass fibres using hot sodium hydroxide. Composites Part A: Applied Science and Manufacturing. 2016;87:220-7. 
[13] Jenkins PG, Yang L, Liggat JJ, Thomason JL. Investigation of the strength loss of glass fibre after thermal conditioning. Journal of Materials Science. 2014;50(3):1050-7.

[14] Pender K, Yang L. Investigation of catalyzed thermal recycling for glass fiber-reinforced epoxy using fluidized bed process. Polymer Composites. 2019.

[15] Yang L, Thomason JL. Effect of silane coupling agent on mechanical performance of glass fibre. Journal of Materials Science. 2013;48(5):1947-54.

[16] Yang L, Thomason JL, Zhu W. The influence of thermo-oxidative degradation on the measured interface strength of glass fibre-polypropylene. Composites Part A: Applied Science and Manufacturing. 2011;42(10):1293-300.

[17] Thomason JL, Yang L. Temperature dependence of the interfacial shear strength in glass-fibre epoxy composites. Composites Science and Technology. 2014;96:7-12.

[18] Bashir ST, Yang L, Anderson R, Tang PL, Liggat JJ, Thomason JL. A simple chemical approach to regenerating the strength of thermally damaged glass fibre. Composites Part A: Applied Science and Manufacturing. 2017;102:76-87.

[19] Nagel U. The processing and characterisation of recycled glass fibre composites. UK: University of Strathclyde; 2016.

[20] Fenwick N. Recycling of composite materials using fluidised bed processes [PhD]: University of Nottingham; 1996.

[21] Kennerley JR, Kelly RM, Fenwick NJ, Pickering SJ, Rudd CD. The characterisation and reuse of glass fibres recycled from scrap composites by the action of a fluidised bed process. Composites Part A: Applied Science and Manufacturing. 1998;29(7):839-45.

[22] Kennerley J. Recycling fibres recovered from composite materials using a fluidised bed process [PhD]: University of Nottingham; 1998.

[23] Gupta PK. Strength of glass fibers. In: Elices M, Llorca J, editors. Fiber Fracture. Oxford: Elsevier Science Ltd; 2002. p. 127-53.

[24] Feih S, Mouritz AP, Case SW. Determining the mechanism controlling glass fibre strength loss during thermal recycling of waste composites. Composites Part A: Applied Science and Manufacturing. 2015;76:255-61.

[25] Thomason JL, Kalinka G. A technique for the measurement of reinforcement fibre tensile strength at sub-millimetre gauge lengths. Composites Part A: Applied Science and Manufacturing. 2001;32(1):85-90.

[26] Bashir ST, Yang L, Liggat JJ, Thomason JL. Kinetics of dissolution of glass fibre in hot alkaline solution. Journal of Materials Science. 2017.

[27] Liu J, Jiang M, Wang Y, Wu G, Wu Z. Tensile behaviors of ECR-glass and high strength glass fibers after $\mathrm{NaOH}$ treatment. Ceramics International. 2013;39(8):9173-8.

[28] Friedrich M, Schulze A, Prösch G, Walter C, Weikert D, Binh NM, et al. Investigation of Chemically Treated Basalt and Glass Fibres. Microchimica Acta. 2000;133(1):171-4.

[29] Wei B, Cao H, Song S. Tensile behavior contrast of basalt and glass fibers after chemical treatment. Materials \& Design. 2010;31(9):4244-50.

[30] Spierings GACM. Wet chemical etching of silicate glasses in hydrofluoric acid based solutions. Journal of Materials Science. 1993;28(23):6261-73.

[31] Scheffler C, Förster T, Mäder E, Heinrich G, Hempel S, Mechtcherine V. Aging of alkali-resistant glass and basalt fibers in alkaline solutions: Evaluation of the failure stress by Weibull distribution function. Journal of Non-Crystalline Solids. 2009;355(52-54):2588-95.

[32] Thomason JL. Interfaces and interfacial effects in glass reinforced thermoplastics. In: Proceedings of 28th Risø International Conference on Materials Science. Roskilde, Denmark, Conference, Conference 2007. p. 75-92.

[33] Min CY, Q. Chen, Yuan XH, Xu ZW. Preparation and Interfacial Properties of Glass Fiber/Polypropylene Microcomposites. Journal of Thermoplastic Composite Materials. 2011;24:17383.

[34] Liu XM, Thomason JL, Jones FR. The Concentration of Hydroxyl Groups on Glass Surfaces and Their Effect on the Structure of Silane Deposits. Silanes and Other Coupling Agents, Volume 5: CRC Press; 2009. p. 25-38. 
[35] Zhuravlev LT. Surface characterization of amorphous silica-a review of work from the former USSR. Colloids and Surfaces A: Physicochemical and Engineering Aspects. 1993;74(1):71-90.

[36] Mäder E, Pisanova E. Characterization and design of interphases in glass fiber reinforced polyproplyene. Polymer Composites. 2000;21(3):361-8.

[37] Mäder E, Freitag KH. Interface properties and their influence on short fibre composites. Composites. 1990;21(5):397-402.

[38] Mäder E, Jacobasch HJ, Grundke K, Gietzelt T. Influence of an optimized interphase on the properties of polypropylene/glass fibre composites. Composites Part A: Applied Science and Manufacturing. 1996;27(9):907-12.

[39] Nygård P, Redford K, Gustafson C-G. Interfacial strength in glass fibre-polypropylene composites: influence of chemical bonding and physical entanglement. Composite Interfaces. 2002;9(4):365-88.

[40] Nagel U, Yang L, Kao CC, Thomason JL. Effects of Thermal Recycling Temperatures on the Reinforcement Potential of Glass Fibers. Polymer Composites. 2016.

[41] Minty RF, Thomason JL, Yang L. The role of the epoxy resin : curing agent ratio on composite interfacial strength and thermal performance. European Conference on Composite Materials 17. Munich2016.

[42] Rudzinski S, Häussler L, Harnisch C, Mäder E, Heinrich G. Glass fibre reinforced polyamide composites: Thermal behaviour of sizings. Composites Part A: Applied Science and Manufacturing. 2011;42(2):157-64.

[43] Gao P, Ward Y, Su KB, Weng LT. Effects of chemical composition and thermal stability of finishes on the compatibility between glass fiber and high melting temperature thermoplastics. Polymer Composites. 2000;21(2):312-21.

[44] Pham Q-T, Chern C-S. Thermal stability of organofunctional polysiloxanes. Thermochimica Acta. 2013;565:114-23.

[45] Iglesias JG, González-Benito J, Aznar AJ, Bravo J, Baselga J. Effect of Glass Fiber Surface Treatments on Mechanical Strength of Epoxy Based Composite Materials. Journal of Colloid and Interface Science. 2002;250(1):251-60.

[46] Kim J-K, Mai Y-W, Mai Y-W. Chapter 2 - Characterization of interfaces. Engineered Interfaces in Fiber Reinforced Composites. Oxford: Elsevier Science Ltd; 1998. p. 5-41.

[47] Khoun L, Hubert P. Cure shrinkage characterization of an epoxy resin system by two in situ measurement methods. Polymer Composites. 2010;31(9):1603-10.

[48] Yang L, Thomason J. The role of residual thermal stress in interfacial strength of polymer composites by a novel single fibre technique. In: Proceedings of 15th European Conference on Composite Materials. Venice, Italy, Conference 24-28 June 2012, Conference 2012.

[49] Meng F, McKechnie J, Turner TA, Pickering SJ. Energy and environmental assessment and reuse of fluidised bed recycled carbon fibres. Composites Part A: Applied Science and Manufacturing. 2017;100:206-14.

[50] Song YS, Youn JR, Gutowski TG. Life cycle energy analysis of fiber-reinforced composites. Composites Part A: Applied Science and Manufacturing. 2009;40(8):1257-65. 